\title{
Interactive comment on "Temporal changes in snow albedo, including the possible effects of red algal growth, in northwest Greenland, simulated with a physically based snow albedo model" by Yukihiko Onuma et al.
}

\section{Daniel Remias (Referee)}

daniel.remias@fh-wels.at

Received and published: 27 December 2019

This study links field observations of arctic snow packs at Greenland with phenomena influencing the surface albedo and thus alterations of melting rates with a mathematical model proposed by the authors. The model is intended to explain the role, respectively to forecast the consequences of different surface concentrations mineral dust, black carbon and organic impurities (mainly snow algae) on the seasonal melting rates. The questions of this work are of very high ecological relevance, taking global warming into account, and in this special case the fate of the Greenland Ice Sheet. Several im- 
portant studies recently dealt with albedo changes of bare glacier ice, however partly neglecting the role of decreased albedo of snow on these glaciers, which will lead to earlier exposure of the glacier surfaces in the ablation zone during the melting season. The proposed model is feasible and a first good step for performing simulation of scenarios. As for every model, improvements will likely follow to make it more robust, and satellite data generally needs more accurate supplementation of field data acquired in situ. In general, false positive results have to be excluded. In the case of this work, one distinct glacier has been sampled during one season. My review will focus on biological aspects; I am not a specialist for albedo or mathematical simulations. The main issue of this manuscript is that the authors will have to consider the biology of algae causing red snow worldwide in more detail, and as a consequence, the model of snow algae "growth on snow surfaces" (which does practically not take place) has to be modified. Regarding terminology, "red algae" and "bloomings" should be avoided throughout the manuscript, and correctly "red snow algae" or better "blooms of red snow" should be used. Consequently, the title could be altered to i.e. "Temporal changes in snow albedo, including the possible effect of algae causing red snow, simulated with a physically based model" The globally most common algal species causing the well-known red snow phenomenon, also at Greenland, has been described recently as Sanguina nivaloides, and consequently "Chlamydomonas nivalis" should be avoided from now on. The according reference to be incorporated: Procházková et al. 2019 (https://doi.org/10.1093/femsec/fiz064). Likewise, the newest, updated general review for snow algae can be included: Hoham \& Remias (https://doi.org/10.1111/jpy.12952; succeeding Hoham \& Duval 2001). In these references, the authors can learn that the spherical red cysts which are abundant on snow surfaces, do not cleave at the surface during the melting season. Cell division takes place only early in the season when the population has not yet reached the still white surface, but the bottom snow is already water logged after the end of winter. This has a significant consequence for the proposed "snow algae growth factor": it does not exist! But from where comes the evident increase of seasonal cell concentration of such blooms? The only explanation 
in my mind is, given that the algae population stays about the same during snowmelt (except that cell diameter will increase to a certain extend), that the volume of snow decreases due to melting (and partly sublimation). Thus, the cell numbers per snow volume increase only passively in the case of red cysts. For creating a model regarding the albedo issues caused by snow algae, the theory can be kept but renamed to i.e. "accumulation model". In this manuscript, the "typical" cell concentration per red snow volume is mentioned several times. But what is typical? First of all, it depends on the location of the ecosystem. Coastal snow fields are usually affected by local nutrient input and may have striking blood red coloration, whereas oligotrophic alpine and polar snow has much lower abundances, causing a more pink snow. Moreover, the concentration of the organic impurities on the snow surface can also be influenced by meteorological events like precipitation, and the authors should discuss this aspect. Melting surface snow has temperatures about 0.5 to $1 \mathrm{C}$ in all studies I know. Therefore, why were calculations performed simulating an elevated snow temperature of $+1.5 \mathrm{C}$ ? This should be physically impossible, and thus I suggest removing this hypothetical data from the manuscript, and likewise change fig. 7.

Detail comments: Line 16, use Sanguina nivaloides instead of Chlamydomonas nivalis throughout Line 27: Why should this albedo model only be valid for snow covers in Greenland? Could it be applied elsewhere? Line 41: visible is from 400 to $700 \mathrm{~nm}$ Line 47: "of" instead "in" the Greenland Ice Sheet Line 50: insert "algae" to the list in brackets Line 52: insert "in" after "might be present" Line 57: Start sentence with "The ..." Line 67: reference Yallop et al. 2012 is about glacier algae, not about snow algae Line 68: delete "and ice" for snow algae. Line 70: give reference Hoham \& Remias instead of Hoham \& Duval Lnie 71: use Sanguina nivaloides instead of Chlamydomonas nivalis and include reference Procházková et al 2019 Line 74: "algal blooms have" instead of "algal blooming has" Line 78: "cellular pigment composition", delete "in cell" Line 84 \& 93: reformulate as explained earlier: the algal abundance on surface is not due to growth but due to concentration. E.g. "accumulation model" Line 191: The mean cell radius was $11.4 \mu \mathrm{m}$ - based on algae from the study site? Please state. Elsewhere in 
the manuscript, a different cell size number based on an older study of Onuma et al. was given. Line 237: the decrease of OC on days 197 and 209 should be discussed, and please consider meteorological events like precipitation as a causer? Lines 240 245: The correlation between OC concentration and snow algae abundance appears to be obvious. Still, despite high significance, other organisms can also contribute to OC like bacteria, and in this habitat most likely, yeast-like fungi. This should be at least briefly discussed (e.g. line 285: the formula is not a proof that snow algae are the main constitute of OC in snow - though this is apparent for this study). Since fungal blooms depend on the snow algae, there could be a stable correlation as well. Line 285: "constituent" instead of "constitution" Line 289: please explain/hypothesise how algae-free snow contains significant amount of $\mathrm{OC}$ at a remote place of Northwestern Greenland. Long-distance deposition? Line 296: unneeded repetition of the considered pigments Line 297: "absorption", not "abruption" Line 299: Sentence "The dominant species was ..." is a repetition of results. Line 309: the typical cell concentration of the study site was $4.9 \times 10$ e 4 cells per litre. To my experience, the lower threshold to see snow discolorations by one's eye is about $5 \times 10$ e6. Thus my question, did you see red snow visually at the study site? This should be mentioned in the results. Line 310: delete non-existing reference "Sutton et al. 1972". There exists only a PhD of Mrs. Sutton from that year, a fine work though which was never published as a paper. There are many good papers for the concentration of Sanguina nivaloides in red snow. Chapter 4.3 (lines 316 - 337): I have serious problems with this part. It should either be rewritten or omitted. There are wrong biological assumptions about growth of red snow algal cysts (as stated in the beginning), which simply does not take place on the snow surface. The bloom that you can see is a (physiologically active) resting stage. Chapter 4.4: A "typical" red snow bloom should be defined more clearly. Only two references for average cell numbers are given. Furthermore, Painter et al 2001 is inappropriate in this context, because they clearly state that they did not any field measurements. Moreover, the number taken from Lutz et al 2014 from location MIT-17 is not the average value for red cysts in that study, but a rather low value for a bloom. For being repre-

Printer-friendly version

Discussion paper
Interactive comment 
sentative, I strongly recommend to include certain further studies of "Chlamydomonas nivalis" and then recalculate the albedo reduction of a "typical" red bloom. Line 353: Start sentence "The phenolic pigments of glacier algae have a broader bandwidth of spectral absorption than the carotenoids of S. nivaloides". Instead of citing Dial et al. 2018, which is rather a deductive/theoretical work, a reference showing real spectral data is more appropriate (e.g. Fig. 13.6 in Remias 2012, Springer Vienna) Line 363: Again, Sutton 1972 is not a paper and Painter et al 2001 give no numbers to cite for. Line 388: replace "but" with "and" Chapter 4.8: Needs to be updated. Please think over the "snow algae growth model" and the sense of using hypothetical high snow temperatures for any calculations. Growth of snow algae takes place in deep layers of snow with very constant conditions around $0.5^{\circ} \mathrm{C}$. The air temperature plays generally no big role since the snow pack starts to be water logged from the bottom, and this occurs earlier than air temperatures raise above zero. Line 586: Reference Painter et al 2001 incomplete, authors missing. "Thomas" instead of Thimas".

Legend to fig 1: "sampling site", not "sites" Legend to fig. 5: say "Temporal changes in algal cell concentration and ..." Figure 7: This is a bit vague considering the theory of cell growth and snow temperatures of $+1.5^{\circ} \mathrm{C}$

Please also note the supplement to this comment:

https://www.the-cryosphere-discuss.net/tc-2019-263/tc-2019-263-RC1-

supplement.pdf

Interactive comment on The Cryosphere Discuss., https://doi.org/10.5194/tc-2019-263, 2019.

Printer-friendly version

Discussion paper 